\title{
New ideas in asthma and allergy research: creating a multidisciplinary graduate school
}

\author{
Bengt Björkstén, Göran Graninger, \\ and Gunilla Jacobsson Ekman \\ Centre for Allergy Research, Karolinska Institutet, Stockholm, Sweden
}

\begin{abstract}
The spring term of 2001 saw the start of a new, unique graduate research training program at the Centre for Allergy Research at the Karolinska Institutet in Stockholm, Sweden. The program was created to bridge the gaps between basic, clinical, social, and behavioral sciences and to establish a global approach to the study of asthma and allergy. A reflection, two years on, discusses the strategies that are key to this model's success and the challenges in introducing a multidisciplinary research program.
\end{abstract}

J. Clin. Invest. 112:816-820 (2003). doi:10.1172/JCI200319798.

Asthma, allergy, and other conditions characterized by hypersensitivity represent rapidly growing health problems in industrialized countries and today affect about $30 \%$ of the population under 30 years of age. The underlying mechanisms of the pathophysiology of these conditions remain unclear. Like other complex and chronic diseases, asthma and allergy affect the individual and society in many ways, e.g., utilization of health care, constraints or changes to lifestyle, individual and societal financial burden, building construction, and environmental planning. Disease management attracts public attention, both at a national level and from international organizations such as the WHO. Despite high levels of morbidity and increased

Address correspondence to: Bengt Björkstén, Centre for Allergy Research Nobels väg 15A, Karolinska Institutet, SE-171 77 Stockholm, Sweden. Phone: 46-8-524-869-56;

Fax: 46-8-31-58-23;

E-mail: Bengt.bjorksten@Cfa.ki.se.

Conflict of interest: The authors have declared that no conflict of interest exists.

Nonstandard abbreviations used:

Karolinska Institutet (KI); Centre for

Allergy Research (Cfa). public awareness, research initiatives focused on these conditions are almost exclusively limited to a few clinical and preclinical disciplines. Generally, allergy has a rather low biomedical research profile compared with, for example, HIV/AIDS, cancer, and heart disease in both industry and graduate and postgraduate education in medical school, and it is even less prominent in other relevant disciplines, such as nursing, and social and behavioral science. Major discoveries in basic science, regarding the relationship between asthma and allergy and $\operatorname{IgE}$, chemokines, leukotrienes, and NO levels in exhaled air, have provided us with a much better understanding of the pathophysiological mechanisms underlying these conditions and subsequently resulted in significant improvement in diagnostic procedures and symptomatic treatment. However, we still lack an understanding of the causes of asthma and allergy, e.g., how the environment and lifestyle factors influence the incidence, prevalence, and severity of disease. We need to know more about coping strategies among those affected, and how to create a healthy indoor and outdoor environment. Based on the complexity of these diseases, it is reasonable to suspect that breakthroughs in the prevention and treatment of allergy will be the result of multidisciplinary collaboration and successful translation of basic research to clinical development.

Research has traditionally been organized into disciplines, and crossing interdisciplinary borders has not been a common research strategy (1). While traditional research approaches have been very successful and have led to major discoveries, it has become increasingly clear that many problems are complex by nature and require broad collaboration in order to be identified and solved $(2,3)$. Therefore, a multi- or interdisciplinary approach, involving disciplines that traditionally never meet in joint research, must be developed to achieve the best quality, creativity, and productivity. Contrary to expectation, such approaches are rarely found within the university system. Creating a novel approach to postgraduate training and other research in a university is not always easy. One challenge for today's university is to foster multi- and interdisciplinary research (1).

\section{Creation of the Centre \\ for Allergy Research}

In 1998, the Swedish Foundation for Health Care Sciences and Allergy Research invited the medical faculties in Sweden to submit an application to develop a center that would bridge clinical and basic allergy research, establish research activities in conjunction with primary patient care, and offer postgraduate education. Established in 1994, the Foundation's main goal is the promotion of research and research education in the fields of caring and nursing as well as research and research education directed toward allergy. After 
submitting an application, which documented considerable intellectual and financial resources within several of the research fields that are relevant to the study of allergy, the Karolinska Institutet (KI) in Stockholm was assigned by the Foundation to develop the Centre for Allergy Research (Cfa).

The Cfa was created to provide bridges among basic, clinical, social, and behavioral sciences and to establish collaboration with experts in economics and technology as they relate to allergy and other conditions characterized by hypersensitivity. Research groups with allergy-related projects at the KI were encouraged to form networks to jointly identify problems from an allergy perspective, rather than applying exclusively intradisciplinary approaches in areas such as immunology, physiology, or pharmacological treatment. About 40 research teams, comprising over 200 people, have joined the $\mathrm{Cfa}$, and about 40 scientists and clinicians are currently involved in research and teaching in one of the various networks. The Stockholm County Council, which is responsible for providing and overseeing health services available in metropolitan Stockholm, actively participated in the establishment of the Cfa and committed considerable financial support to its creation. The County Council's continuing commitment to the Cfa has contributed significantly to the center's interdisciplinary research.

\section{Graduate research training}

A four-year graduate training program was launched in 2001 with the aim of educating a new generation of researchers that would work toward earning a PhD from the perspective of allergy, rather than from the perspective of traditional disciplines. This would ideally achieve three main goals: (a) broaden awareness and increase knowledge about allergy in fields other than traditional biomedicine; (b) train a new generation of researchers; and (c) encourage cooperation among senior scientists who would share responsibility as supervisors. Previous interdisciplinary education and teamwork in medical schools have mostly focused on graduate training, rather than research $(4,5)$.

To date, 21 graduate students have been admitted to the program, based on their curriculum vitae, an autobiographical essay, and personal interview. They were selected among over 120 applicants by a panel of eight people at the KI, chaired by the director. The students have a diverse educational background, including degrees in basic sciences, medicine, nursing, public health, dietetics, economics, psychology, and sociology. Many students possess degrees in more than one of these areas. The first semester consists of courses exploring allergy from a variety of perspectives (see "Studying allergy from a new perspective"). Two courses, "The philosophy of science from an interdisciplinary perspective" and "How to present research", ran over a four-month period. It has been suggested that studying a subject from the perspective of multiple disciplines, or "shared learning," at an early stage in graduate training could ultimately facilitate interdisciplinary collaboration in research (4).

During the introductory period, the students are continuously exposed to ongoing research at the KI and are encouraged to nominate research problems that they would want to address as members of one of the research networks. Four of these networks were given priority by an evaluation committee composed of five senior scientists from other Swedish universities and representative of different disciplines. The research projects are then ideally developed in collaboration between the student and two or three supervisors, one of whom should have a research background clearly different from that of the main supervisor.

In order to maintain and further develop openness toward multidisciplinary collaboration, the students regularly meet to discuss their projects, and they also attend weekly research seminars on specific topics. Ongoing interaction and maintenance of a positive group dynamic among the students are essential to maintain a multidisciplinary approach in identifying problems and discussing research progress. A continuous interaction between the students and their supervisors is also crucial, encouraging students to maintain focus on asthma and/or allergy rather than to limit themselves to a single discipline.

\section{Opportunities}

Some of the unique benefits and opportunities associated with a multidisciplinary approach to the postgraduate study of disease are listed in Table 1.

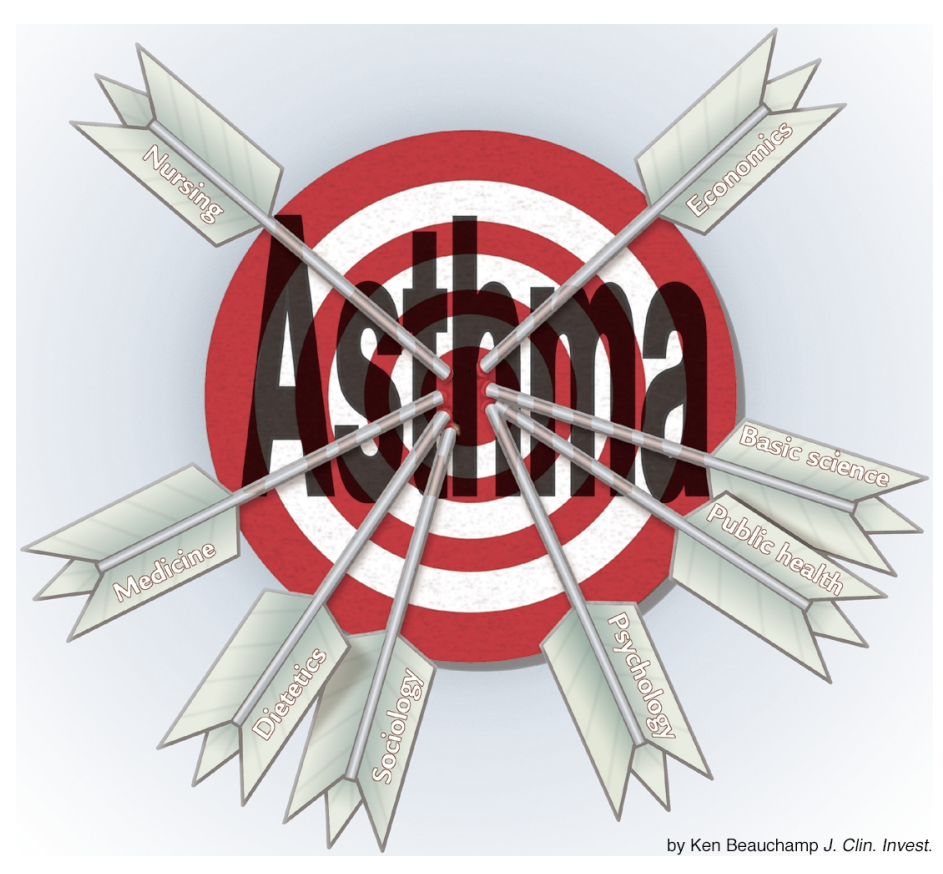


Table 1

Unique benefits and opportunities associated with a multidisciplinary approach to postgraduate education

Team composition

Interaction over a broad field is attractive to prospective graduate students

An intellectually stimulating environment is created

Knowledge is gained from many fields relevant to allergy

Problem solving Hitherto unknown problems are identified by application of new perspectives Previously unsolved problems are approached from a new angle

Solution development

Truly innovative approaches may evolve

Multidisciplinary interaction ensures the development of highly relevant solutions

Strong support from the general community facilitates funding

To date, two classes of students have begun the program. It is obviously attractive to prospective graduate students, several of whom were not content with traditional programs currently offered at the $\mathrm{KI}$ and other universities. Thus it appears to attract outstanding students who might otherwise seek nonacademic careers. Its interdisciplinary method is perceived by both students and many scientists as intellectually stimulating, and experienced researchers have expressed that their approach to the study of allergy has been influenced and their perspective broadened by their involvement in or knowledge of the program. The collaboration among many disciplines should facilitate the development of competent researchers who are aware of all fields relevant to asthma and allergy. This contrasts with the current situation, where knowledge is dispersed within the traditional disciplines. There is strong support for the Cfa among both patient organizations and those individuals or groups responsible for prioritizing and distributing funding for research and health care. Hopefully, the center's contribution to the study and management of asthma and allergy will increase public understanding of the need for multidisciplinary research, and also the need for funding in times of financial restraint.

\section{Challenges}

The initial application to develop the Cfa included words and phrases that are commonly used in calls for interdisciplinary research: "relevance to society," "multidisciplinary," "interdisciplinary," "focus on allergy in a broad sense," "patient focused," and "novel and co-ordinated interaction rather than expanding current activi- ties." The interpretation of these words and phrases was questioned and caused some conflict among researchers enrolled in the project. Once the funds to create the Cfa were allocated by the Swedish Foundation for Health Care Sciences and Allergy Research, there was a widespread expectation among researchers at the KI that these funds would be distributed among the groups that were already engaged in allergy research, rather than be partly allocated toward recruitment of scientists from other disciplines who had not previously addressed allergy. It was felt by some enrolled researchers that the key words used in the application had served their purpose once the money had been allocated to the KI, and that they were now free to use the funds to continue research along traditional lines. The chancellor and board of the KI, however, decided to pursue the route indicated in the application and appointed an externally recruited director to establish this route at the Cfa.

External scientists with expertise in interdisciplinary and problem-focused research participated in a series of seminars, in which they pooled their experience from previous initiatives aimed at establishing interdisciplinary programs and postgraduate training in faculties other than medicine $(1,2$, 6). Participants included scientists with a traditional approach to medical research, as well as proponents of a holistic view of allergy research, the latter of whom suggested that behavioral and social sciences and nursing be added to the disciplines within biomedicine. Multidisciplinary postgraduate research training was determined as the highest priority for funding to the Cfa, rather than grants for allergy research in general.

A truly multidisciplinary approach requires leadership and vision. Multidisciplinary cooperation demands generosity and an open mind, as well as research excellence. The participants must acknowledge that problems can be defined differently depending on the perspective. Such understanding requires training. Traditionally, training in biomedical research centers almost exclusively on the laboratory bench or regards a narrowly defined clinical problem, with the aim of developing a diagnostic procedure or treatment for a specific disease.

At the Cfa, the forces pulling students back into traditional disciplines are strong. To maintain the focus on asthma and allergy rather than on an academic discipline, students must develop shared visions. It is also essential for the main supervisor to stay open to the multidisciplinary approach. The introduction of novel methods of postgraduate training is bound to meet resistance from some members of the research community. One way to objectively assess the degree of participation by the researchers at the KI is to assess the resources that the participating senior scientists allocate to the research of the graduate student. Motivating faculty members to learn about new approaches is an ongoing challenge that requires clear strategies for implementation (4).

Shortly after the first students were admitted to the $\mathrm{Cfa}$, it received criticism. Some members of the research community claimed that it was engaged in administration rather than research, that funds were allocated without proper peer review, and that 


Studying allergy from a new perspective
Courses offered in the first six months of the program include:
Allergy from a global health perspective
Nursing care and quality of life with a focus on asthma and allergies
Health economics and health research with a focus on asthma,
allergies and other hypersensitivity
Skin allergy and inflammation
Psycho-neuroimmunology
The philosophy of science from an interdisciplinary perspective
How to present research

the multidisciplinary research would be of low quality. These complaints were voiced well before any results could possibly have been demonstrated, and despite the involvement of external reviewers. It was asserted that, rather than being wasted on this project, the funds should be allocated to established groups for continuation of their projects at the research front line. "Front line," however, was not defined, and it was unclear whether it should be defined only within particular disciplines or in collaboration with scientists from other disciplines and spokespersons for public interests.

The criticism was expected, as similar objections have been raised when other interdisciplinary programs have been launched elsewhere, e.g., the Tema Research Institute, a large department created at Linköping University in Sweden in the 1980s to facilitate research in several areas and bridge the gaps between social, behavioral, and natural sciences, as well as the humanities. Attempts in many other countries to address environmental issues through an interdisciplinary approach have resulted in similar reactions $(6,7)$. Such criticism has typically been expressed as if it were empirically founded; however, it has usually been based on premature judgments, assumptions, and even guesses. Universities are usually poorly prepared to modify traditional research approaches in order to solve complex problems in modern society. An adaptation to such challenges would require a willingness to reorganize traditional departments in forms other than those deriving from traditional disciplines $(1,8)$. Furthermore, qualitative methods of analysis as a complement to tradi- tional quantitative methods are generally not highly valued in a biomedically oriented faculty (5).

There are several organizational and administrative issues that must be solved before the Cfa's model approach can be considered a success. Individually these issues would appear to be less important, but taken together they disturb daily productivity and progress. The admittance procedure requires review and modification. Currently, Cfa students are enrolled in one of the departments at the KI. This gives proponents of traditional disciplinary research power over the program and creates uncertainty among the students regarding who ultimately oversees their research project, education, and future. The name of the awarded degree is also of some concern. Will students graduate with a $\mathrm{PhD}$ in the "Science of Allergy" or in a traditional discipline? The traditional academic reward system is a matter of further concern, as the peer review process tends to appreciate intradisciplinary achievements more than the results of interdisciplinary efforts, the latter sometimes being more difficult to fully comprehend by a single assessor.

\section{The future}

The need for interdisciplinary research was clearly seen by the Swedish Foundation for Health Care Sciences and Allergy Research and the leadership of the KI and the Stockholm County Council, and without their focused efforts the Cfa would not have been created. Through their ongoing ideological support, the center has retained a broad and interdisciplinary approach, despite criticism from proponents of the traditional approach to biomedical research. It is a prereq- uisite for continued financial support that the research performed and the education obtained at the Cfa are excellent. However, this is not enough to secure the future of the center.

In the future it will also be important to continue making the Cfa's activities and finances fully transparent even to those who criticize it. Only by granting such access will the Cfa, step by step and without sacrificing its profile, gain the confidence of the traditional-research community. Such confidence is a prerequisite for long-term excellence in research. Therefore, external members of the scientific community should be encouraged to review the organization's activities. It is important, however, that these reviewers possess sufficient expertise and a strong international standing. Furthermore, to avoid disciplinary bias, any group of external reviewers should comprise scientists from several disciplines and faculties.

The Cfa will be vulnerable to general criticism until the first students have completed their theses with due external review and have had an opportunity to show that they have received an education that meets or exceeds international standards. Only then can any criticism be based on empirical data. In the interim, the innovative potential of the center must be demonstrated. This demonstration may include current endeavors to establish a novel interdisciplinary center for the study of health problems related to the indoor environment, their causes, and approaches to their prevention. This concept is currently being developed by a team of researchers from the KI, the Royal Institute of Technology, and the Department of Psychology at Stockholm University, and authoritative representatives from the building industry. Furthermore, collaboration is currently being developed between the $\mathrm{Cfa}$ and leading universities abroad, focusing on joint postgraduate and postdoctoral programs.

We believe that the Cfa cannot depend entirely on support from within the university, e.g., from a traditional faculty board. It is essential to establish a strong board of direc- 
tors with integrity and a chairperson with the capacity to raise funds, rally political support, and defend the interdisciplinary program from strong proponents of traditional research within the university. Once the classes of 2005 and beyond have graduated, received further postdoctoral training, and become independent scientists, they will have the competence to formulate and address novel research questions. Only the future will tell whether truly innovative approaches to asthma and allergy will result from multidisciplinary education such as that offered by the Cfa.

\section{Acknowledgments}

The Centre for Allergy Research gratefully acknowledges funding from the Swedish Foundation for Health Care Sciences and Allergy Research, the Stockholm County Council, the Karolinska Institutet, and Pharmacia Diagnostics AB.

1. Gibbons, M., Nowotny, H., Scott, P., and Swarzmann, S. 1994. The new production of knowledge: the dynamics of science and research in contemporary soci eties. Sage Publications Ltd. London, United Kingdom. 192 pp.

2. Mewborn, D., et al. 2002. Expanding the "great conversation" to include arts and sciences faculty. Innovative Higher Education. 27:39-51.

3. Camblin, L.J., and Steger, J. 2000. Rethinking faculty development. Higher Education. 39:1-18

4. Hall, P., and Weaver, L. 2001. Interdisciplinary education and teamwork: a long and winding road. Med. Educ. 35:867-875.

5. Larivaara, P., et al. 2000. From biomedical teaching to biophysical education: a process of change in a Finnish medical school. J. Interprof. Care. 14:375-385

6. Graninger, G., and Lind, I. 1985. The Faculty of Theme Research at Linköping University, Sweden. In Interdisciplinary revisited. Re-assessing the concept in the light of institutional experience. L. Levin and I. Lind, editors. OECD/CERI, Swedish National Board of Universities and Colleges and Linköping University. Liber Publishers. Stockholm, Sweden. 28-45.

7. Graninger, G. 2002. Från idé till framgångsrik forskning: några synpunkter på tillkomsten av tema Teknik och social förändring. In Spänningsfält. L. Sturesson, J. Summerton, K. Ellegård, and S. Beckman, editors. Carlsson Publishers. Stockholm, Sweden. 317-336.

8. Nowotny, H., Scott, P., and Gibbons, M. 2001. Rethinking science: knowledge and the public in an age of uncertainty. Polity Press. Cambridge, United Kingdom. 278 pp. 